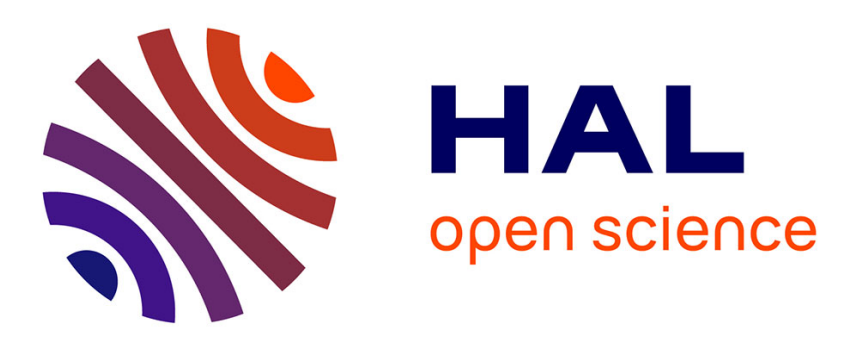

\title{
FERMI SURFACE, TRANSPORT AND SUPERCONDUCTING PROPERTIES OF GRAPHITE INTERCALATION COMPOUNDS
}

\author{
S. Tanuma, K. Higuchi, H. Suematsu, Y. Koike
}

\section{> To cite this version:}

S. Tanuma, K. Higuchi, H. Suematsu, Y. Koike. FERMI SURFACE, TRANSPORT AND SUPERCONDUCTING PROPERTIES OF GRAPHITE INTERCALATION COMPOUNDS. Journal de Physique Colloques, 1978, 39 (C6), pp.C6-1104-C6-1105. 10.1051/jphyscol:19786489 . jpa-00217971

HAL Id: jpa-00217971

https://hal.science/jpa-00217971

Submitted on 1 Jan 1978

HAL is a multi-disciplinary open access archive for the deposit and dissemination of scientific research documents, whether they are published or not. The documents may come from teaching and research institutions in France or abroad, or from public or private research centers.
L'archive ouverte pluridisciplinaire HAL, est destinée au dépôt et à la diffusion de documents scientifiques de niveau recherche, publiés ou non, émanant des établissements d'enseignement et de recherche français ou étrangers, des laboratoires publics ou privés. 
S. Tanuma, K. Higuchi, H. Suematsu and Y. Koike

Institute for Solid State Physics, University of Tokyo, Rappongi, Minatoku, Tokyo, 106 Japan

Résumé.- On a construit la surface de Fermi du composé intercalaire graphite-potassium $C_{48} \mathrm{~K}$ et $C_{36} \mathrm{~K}$ afin qu'elle soit adaptée au cycle observé de Haas-van Alphen. L'étude de la résistance magnétique a permis de présenter l'orbite ouverte prévue. On observe la supra-conductivité du composé $\mathrm{C}_{8} \mathrm{~K}$ à $134 \mathrm{mK}$; on trouve une forte anisotropie du $\mathrm{Hc}_{2}$. On étudie aussi les composés graphite-brome par des méthodes similaires.

\begin{abstract}
The Fermi surfaces of graphite-potassium intercalation compounds, $\mathrm{C}_{48} \mathrm{~K}$ and $\mathrm{C}_{36} \mathrm{~K}$, were composed in such a way that the observed de Haas-van Alphen periods were fitted. The predicted open orbits were proved by the magneto-resistance study. Superconductivity of $C_{8} \mathrm{~K}$ compound was observed at $134 \mathrm{mK}$. A large anisotropy of $\mathrm{Hc}_{2}$ was found. Graphite-bromine compounds were also studied by a similar method.
\end{abstract}

Intercalation of atoms or molecules into graphite attracts recent attention /1/ in the wiew points of electronic structure, transport properties, electronic phase changes of superconductivity of CDW possibility and phonon modes. We have investigated low temperature properties of $\mathrm{C}_{\mathrm{x}} \mathrm{K}$ and $\mathrm{CBr}_{\mathrm{y}}$ as the typical intercalation compounds of donor and acceptor types respectively. We prepared pseudo-single crystals of $\mathrm{C}_{12} \mathrm{n}^{\mathrm{K}}(\mathrm{n}=4,3,2)$ and $\mathrm{CBr}_{0.021-0.045}$ using highly oriented pyrolytic graphite given by Dr. Moore of Union Carbide Co.. The number $n$ means that $n$ hexagonal carbon layers exists between adjacent intercalated layers to make a superlattice structure along the c-axis, and $\mathrm{n}$ is called the stage number.

The de Haas-van Alphen (dHvA) effect was observed at $1.3 \mathrm{~K}$ in most of the prepared crystals. Figure 1 shows the field angle dependence of the dHvA periods. The dashed lines ( $\cos \theta$ ) correspond to cy1indrical Fermi surfaces (FS). The lines are adjusted with the experimental points at $\theta=0^{\circ}$. For the 4 th stage compound $\mathrm{C}_{48} \mathrm{~K}$, five branches $\alpha, \beta, \gamma, \delta$ and $\varepsilon$ are found and their values at $0^{\circ}$ are smaller by two orders of magnitudes than the values of pure graphite $\left(1.60 \times 10^{-5} 0 e^{-1}\right.$ for electron and $2.16 \times 10^{-5} 0 e^{-1}$ for hole). Except the $\varepsilon$-branch which has not enough observed points, every branch suggests rather thin FS. For the most intercalated compound $\mathrm{C}_{8} \mathrm{~K}$ only one value of $3.49 \times 10^{-8} \mathrm{Oe}^{-1}$ is observed at present, which agrees fairly with the calculated value $2.8 \times 10^{-8} \mathrm{Oe}^{-1}$ corresponding to the cylindrical FS in the band calculation by

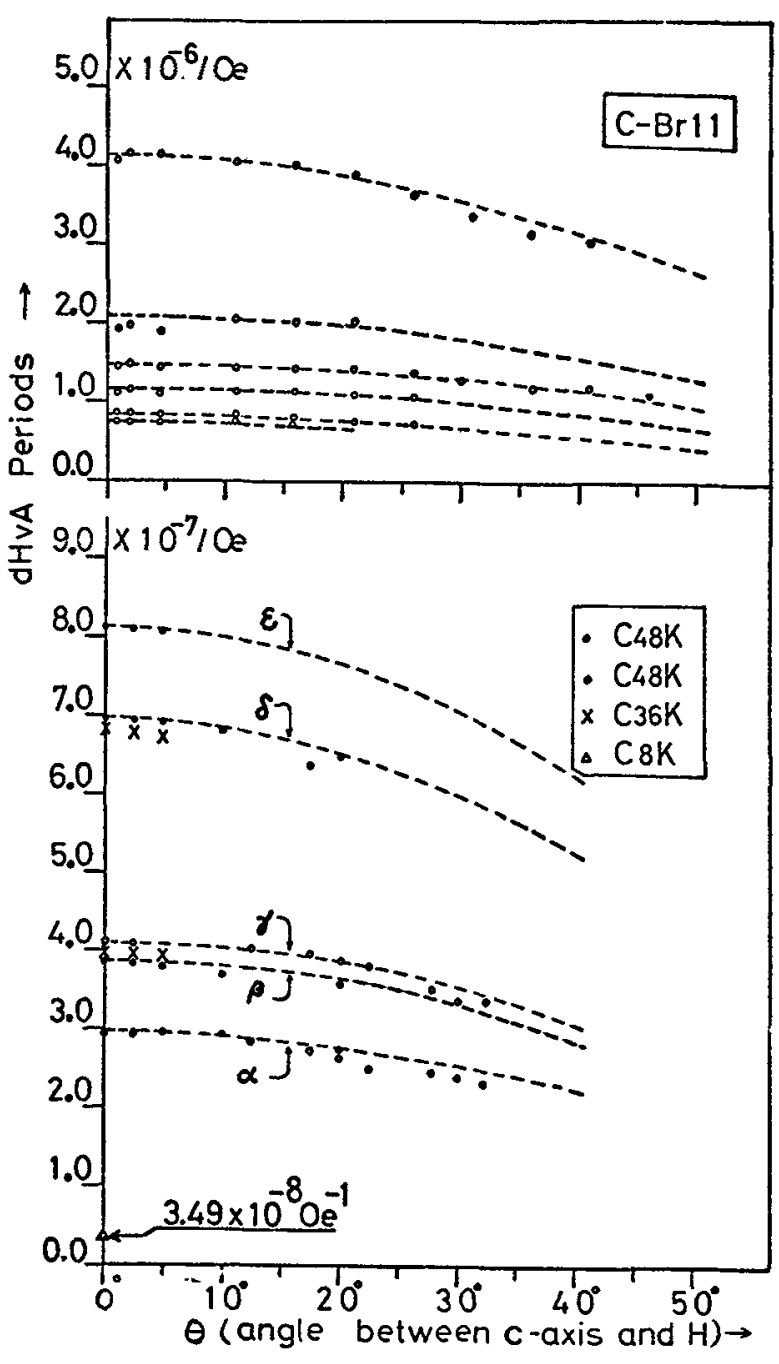

Inoshita et a1. $/ 2 /$. No less dHva period than the $\alpha$-branch is considered to exist in $\mathrm{C}_{48} \mathrm{~K}$ because 
much less period is found in $\mathrm{C}_{8} \mathrm{~K}$ sample of which quality should be worse than high stage compounds; therefore the $\alpha$-branch should correspond to the 1argest FS in $\mathrm{C}_{48} \mathrm{~K}$. We adopted the rigid band model of graphite and let the observed period $2.96 \times 10^{-7} \mathrm{Oe}^{-1}$ at $\theta=0^{\circ}$ in the $\alpha$-branch to fit the sectional area at K-point of the Brillouin Zone (BZ) and we obtained the Fermi energy of $0.42 \mathrm{eV}$ which is compared to $0.018 \mathrm{eV}$ in pure graphite. The calculated FS is much like an ellipsoid in the extended $\mathrm{BZ}$, and the hole FS in graphite disappears.The 4th stage compound has twice the c-axis period of the pure graphite, i.e., the $B Z$ has half the thickness of the original one. We made the $\mathrm{FS}$ of $\mathrm{C}_{48} \mathrm{~K}$ by folding the rigid band $F S$ into the half thick $\mathrm{BZ}$ and introducing energy gaps at the new zone edge. Figure 2 shows the electron FS thus constructed. The figure is drawn as the extended zone scheme and thick line
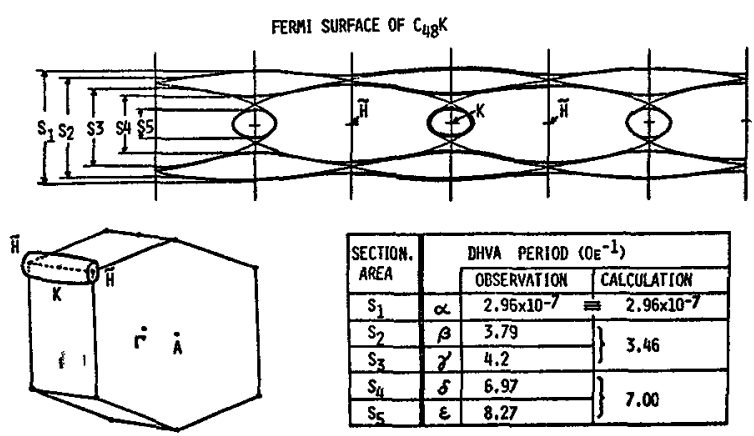

\begin{tabular}{|c|c|c|c|}
\hline \multirow{2}{*}{$\begin{array}{l}\text { SECIION. } \\
\text { AREA }\end{array}$} & \multicolumn{3}{|c|}{ DHVA PERIOD $\left(0 \mathrm{E}^{-1}\right)$} \\
\hline & & OBSERVATIOH & CALCULATIOH \\
\hline$\overline{s_{1}}$ & $\alpha$ & $2.96 \times 10^{-7} \equiv$ & $2.96 \times 10^{-7}$ \\
\hline$s_{2}$ & $\beta$ & 3.79 & \\
\hline$s_{3}$ & $\gamma$ & 4.2 & 3.46 \\
\hline$s_{4}$ & $\delta$ & 6.97 & $7 \mathrm{~m}$ \\
\hline 5 & $\varepsilon$ & 8.27 & \\
\hline
\end{tabular}

shows the FS in the unit zone H̃KH. The three kinds of FS appears ; the smallest one is a closed FS and the other two are open. By fitting the sectional area $S_{1}$ at $K$-point, the observed values of $S_{2}$ to $S_{5}$ are fairly compatible with the rigid band model if we ignore the separations of $S_{2}$ and $S_{3}$ and of $S_{4}$ and $S_{5}$, as is shown in the inserted table in figure 2. The FS of $\mathrm{C}_{36} \mathrm{~K}$ was constructed in a similar way. There were predicted open orbits in $C_{12 n} \mathrm{~K}(\mathrm{n}=4,3,2)$ as well as in $\mathrm{C}_{8} \mathrm{~K} / 2 /$. We measured the field angle dependence of the transverse magneto-resistance at low temperatures and found a hamp or a peak centered at $\theta=90^{\circ}\left(\mathrm{H}_{\perp} \mathrm{c}-\mathrm{axis}\right)$ in contrast to the zero magneto-resistance at $\theta=90^{\circ}$ for pure graphite. This fact proves the existence of the open orbits at this configuration.

The superconductivity of $C_{8} \mathrm{~K}$ was observed on similar samples to the above one. The transition temperature was 134 and $130 \mathrm{mK}$ for two samples. The samples are square shaped lamellar plates of which edge length do depth ratio are about 4 . The values of $\mathrm{Hc}_{1}, \quad\left(\mathrm{Hc}_{1}\right.$ without the correction of demagnetization factor) and $\mathrm{Hc}_{2}$ are $6.0 \mathrm{De}$ and about 50 Oe for $\mathrm{H} / / \mathrm{c}$-axis, and $20 \mathrm{Oe}$ and $\succsim 1 \mathrm{kOe}$ for $\mathrm{H} \perp \mathrm{c}$-axis respectively (Fig. 3). The measured $T_{c}$ in these rather well defined $\mathrm{C}_{8} \mathrm{~K}$ compounds is lower than the

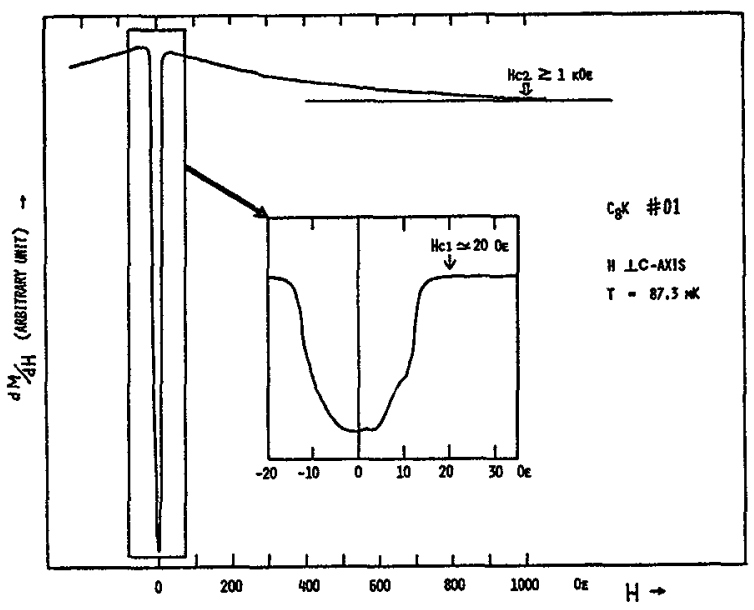

early reported value $550 \mathrm{mK}$ in the sample wet with potassium metal /3/ and higher than the value $80 \mathrm{mK}$ in the powder samples $/ 4 /$.

By the similar experimental investigations on $\mathrm{CBr}_{\mathrm{y}}$ intercalation compounds, we concluded that the residue compounds are multipase. The main compound is probably $\mathrm{C}_{32}\left(\mathrm{Br}_{2}\right)$ irrespective to the $\mathrm{y}$-value. This compound makes islands in the original highly oriented graphite, and the y-value determines the mol.ratio of intercalated to pure graphite.

\section{References}

/1/ Conference on Graphite Intercalation Compounds, 1977, La Napoule

12/ Inoshita, T., Nakao, K. and Kamimura,H., J. Phys. Soc. Jpn 43 (1977) 1237

/3/ Hannay, N.B. et a1., Phys. Rev. Lett. 14 (1965) 225

14/ Kobayashi, M. and Tsujikawa, I., Meeting of Phys. Soc. Japan (1977) 